\title{
Antimicrobial prophylaxis outside the operating theatre, an audit in a university hospital
}

\author{
Jan W. T. Deelen ${ }^{1,2^{*}}$, Caroline E. Visser ${ }^{3}$, Jan M. Prins ${ }^{4}$ and Reinier M. van $\mathrm{Hest}^{5}$
}

\begin{abstract}
Background: The prophylactic use of antimicrobial agents to prevent infections in non-surgical situations has hardly been investigated. We investigate the extent, indications and appropriateness of antimicrobial prophylaxis given outside the operating room in a tertiary care hospital.

Methods: Four point-prevalence surveys were conducted in which all inpatients on that day were screened for the use of prophylactic antimicrobials: medical prophylaxis, prophylaxis around non-surgical interventions and surgical prophylaxis given on the ward. The primary endpoint was the extent of prophylaxis relative to the total number of antimicrobial prescriptions. We also investigated per prescription the presence of a (local) protocol and adherence to these protocols.
\end{abstract}

Results: We registered in total 1020 antimicrobial prescriptions, of which 317 (31.1\%) were given as prophylaxis. 827/ 1020 were antibiotic prescriptions. Of these antibiotic prescriptions, $17.0 \%$ was medical prophylaxis, $2.7 \%$ prophylaxis around non-surgical interventions and 6.9\% surgical prophylaxis administered on a ward. For medical antibiotic prophylaxis, a protocol was present in 125 of 141 prescriptions (88.7\%); the protocol was followed in 118 cases (94.4\%). For prophylaxis around non-surgical interventions and surgical prophylaxis on the wards, protocol presence and adherence rates were 59.1\% and 92.3\%, and $73.3 \%$ and $97.6 \%$ respectively. Of the 96 antiviral and 97 antifungal prescriptions, $42.7 \%$ and 57.8\%, respectively, were medical prophylaxis, of which 95.1 and $96.3 \%$ were prescribed according to protocols respectively.

Conclusions: Antimicrobial prophylaxis outside the operating theatre is responsible for a considerable part of total in-hospital antimicrobial use. For most prescriptions there was a protocol and adherence to the protocols was high. The main targets for improvement were prophylaxis around non-surgical interventions and surgical prophylaxis given on the ward.

Keywords: Antimicrobials, Antibiotics, Antibiotic stewardship, Prophylaxis, Point prevalence survey

\section{Background}

Antimicrobial prophylaxis is an important part of antimicrobial use. Peri-operative antibiotic prophylaxis prevents up to $80 \%$ of surgical site infections [1]. The increasing use of high-dose chemotherapy and non-surgical invasive therapies (cardiology, gastro-enterology) has led to an increase of indications for medical antimicrobial prophylaxis: the

\footnotetext{
* Correspondence: j.w.t.deelen@umcutrecht.nl

${ }^{1}$ Academic Medical Center, Amsterdam, the Netherlands

${ }^{2}$ Pressent Address: Julius Center for Health Sciences and Primary Care, University Medical Center Utrecht, Huispostnr. STRATENUM 6.131, Postbus 85500, 3584 CG Utrecht, the Netherlands

Full list of author information is available at the end of the article
}

prevention of infections in non-surgical situations. These indications have been described in reviews and guidelines [2-4]. They have, however, also been subjected to debate: low level evidence due to a lack of high quality clinical trials has led to different interpretations on what dosage of which antibiotic to use for what indication and for what duration. This carries a serious risk for suboptimal use.

In 2015, the Health Council of the Netherlands concluded that there is a lack of knowledge concerning the extent, indications, and evidence base of medical antimicrobial prophylaxis [5]. Published audits hardly seem to include any in-depth information on medical 
antimicrobial prophylaxis [6-8]. We suspect that it might be responsible for a considerable part of total in-hospital antimicrobial drug use.

In this study, we investigated in a point-prevalence survey the in-hospital use of antimicrobials for prophylaxis given outside the operating theatre in a tertiary care teaching hospital. The goals were threefold: to investigate the extent of prophylaxis, the indications for prophylaxis per medical subspecialty and the presence of protocols and guidelines and the adherence to these protocols. This will contribute to the identification of targets for intervention in line with the goals of antimicrobial stewardship.

\section{Methods}

\section{Design and setting}

The study was carried out in June 2015 in the Academic Medical Center in Amsterdam, a tertiary care hospital with 1002 hospital beds. The hematology department performs allogeneic and autologous stem cell transplantation, the surgery department performs complex oncological surgery (e.g. liver resections, Whipple procedures), and there is a kidney transplant unit $(+/-130$ transplantations per year). An antimicrobial stewardship team is present, which monitors the use of restricted antimicrobial drugs. An infectious diseases specialist can be consulted for complex infectious cases. Since this observational pointprevalence study of patient files was performed in the context of a quality improvement project, approval of the medical ethics committee was not required. Patient data were entered anonymously in the study database.

\section{Data collection}

\section{Point prevalence survey}

Four point-prevalence surveys (PPS) of in-hospital antimicrobial use' were performed on four consecutive Mondays, in which all hospitalized patients were analyzed for the use of antimicrobials on that day. PPS quickly give an accessible insight in antibiotic use, and they are used in many studies for identifying targets for improvement [6-10]. The PPS were carried out according to the ECDC technical document on PPS [11]. All antimicrobial prescriptions on the concerning Mondays were included. The intensive care units (neonatal, pediatric and adult) were excluded. Files of admitted patients were manually screened for the use of antimicrobials. On Tuesday, we obtained a list from the computerized medication order entry system of the clinical pharmacy department containing all antimicrobial prescriptions of the previous Monday to confirm and complete the acquired data. We included antiviral and antifungal medication. Surgical prophylaxis administered in the operating theatre was not included.

\section{Classification of prophylaxis}

Prescriptions were separated into two groups: prophylactic and therapeutic prescriptions. Prophylaxis was divided into three groups: medical prophylaxis, prophylaxis around non-surgical interventions (hereafter called medical intervention prophylaxis) and surgical prophylaxis given on the ward (as opposed to prescribed in the operating theatre.) Medical prophylaxis was defined as an antimicrobial prescribed for prevention of an infectious complication of a disease. Medical intervention prophylaxis was defined as an antimicrobial prescribed for preventing infectious complications of a medical intervention or procedure which due to its nature (no incision) cannot be called surgery (e.g., endoscopy or cystoscopy). Surgical prophylaxis given on the ward was defined as any antimicrobial administered on the ward preceding a surgical intervention or administered postoperatively as extended prophylaxis to prevent surgical site infections. Prophylactic antibiotics given after surgery for other reasons than preventing wound infections or surgical complications were classified as medical prophylaxis. Indications of prophylaxis were investigated by reviewing the medical records. When indications were not clear, they were more thoroughly investigated by looking at culture samples, radiology reports and the case notes of consulted specialists.

\section{Protocol presence and adherence}

To evaluate the appropriateness of the prescriptions, we evaluated every prophylactic prescription for the presence of a protocol and assessed the adherence to the protocol. Local antimicrobial guidelines in the Academic Medical Center in Amsterdam (AMC) can be easily found on the intranet and are based on national guidelines, with local additions and changes made according to resistance patterns in the hospital. Other specialist guidelines are also found on the intranet, albeit less organized. We searched the local protocol database for the presence of protocols concerning prophylactic antimicrobial drug use.

Since prophylaxis in neutropaenia should be discontinued when neutropaenia is over or when the patient suffers from an active infection (neutropaenic fever), we investigated whether this prophylaxis was indeed discontinued when necessary. It was also registered when there was a documented reason for deviating from the protocol, which was scored as the motivation of non-adherence. The appropriateness of these cases was judged on a case-by-case basis.

\section{Data analysis}

To report the extent of antimicrobial prophylaxis, 'Days on Therapy' (DoT) are preferably used. In practice, when conducting a PPS, a DoT is equal to a prescription of any dose of any antimicrobial. Therefore, we report data as number of prescriptions. When a patient switched from intravenous to the same oral antibiotic on the day 
of the PPS, this was interpreted as one DoT, but when a patient on a specific day switched from one antibiotic to another, it was interpreted as two DoT, since at least one dose of two different antimicrobials were given that day.

The extent of prophylaxis is reported as a percentage (prophylactic prescriptions/total number of prescriptions *100). The presence of a protocol was assessed for each prescription and is reported as percentage of the total number of prophylactic prescriptions. Likewise, the adherence to protocols was calculated and reported as percentage of prophylactic prescriptions with a protocol. Prophylaxis is reported by medical specialty. Some subspecialties are reported separately (e.g. haematology), in case of a large amount of prescriptions for medical prophylaxis. Since this was an explorative study, further statistical analyses were not performed.

\section{Results}

A total of 1020 antimicrobial prescriptions were retrieved, of which 317 (31.1\%) were considered prophylaxis (Table 1). Medical prophylaxis accounted for 237 prescriptions (23.2\%), 22 prescriptions were prophylaxis in case of medical interventions (2.2\%), and 58 (5.7\%) surgical prophylaxis prescribed on a ward instead of in the operating theatre. When further differentiating into antibiotics, antifungals and antivirals, 827 of 1020 prescriptions were antibiotics. Of these, $220(26.6 \%)$ were prophylaxis, of which 141 were medical prophylaxis (17.0\% of all antibiotic prescriptions), 22 medical intervention prophylaxis $(2.7 \%)$ and 57 surgical prophylaxis (6.9\%). There were 96 antiviral prescriptions, of which 41 were medical prophylaxis (42.7\%), while 56 of 97 antifungal prescriptions were prophylaxis (57.7\%). These were most commonly prescribed in the internal medicine and haematology department.

When looking at protocol adherence in case of antibiotic prophylaxis (Table 2), for medical prophylaxis a protocol was present in 125 of 141 prescriptions (88.7\%), and 118 prescriptions were given according to these protocols (94.4\%). A motivation of non-adherence, in which the choice for that particular prophylaxis was specified in the patient record, was present in only one of seven cases. In the other six cases, there was no information on the reason for the deviation from the protocol. On the haematology department, prophylaxis was stopped when a patient developed fever or was not neutropaenic anymore, while in the children's oncology department there were four cases in which prophylaxis was continued during fever.

For prophylaxis in case of medical interventions, a protocol was present in 13 of 22 cases (59.1\%), which was adhered to in 12 cases (92.3\%). Surgical prophylaxis given on a ward had a protocol presence of $73.7 \%$ and adherence rate of $97.6 \%$.

Antiviral and antifungal prophylaxis were primarily prescribed as medical prophylaxis (100\% and 98.2\%), had a protocol available in $100 \%$ and $98.2 \%$ and an adherence rate to these protocols of $95.1 \%$ and $96.3 \%$ respectively (not shown in table).

Thus, a protocol was present in 276 of 317 prophylactic antimicrobial prescriptions (87.1\%), and 262 of these were according to this protocol (94.9\%). Fourteen of 276 prescriptions $(5.1 \%)$ where a protocol was available deviated from that protocol, which was motivated in only one case. Therefore, in 13 prescriptions (4.7\%) the protocol was not followed, without documentation. In five cases, prophylaxis was motivated despite absence of a protocol.

Table 3 shows the number of antibiotic prescriptions per medical subspecialty. Haematology was the top prescriber, counting more prescriptions than no. 2 (paediatric oncology) and 3 (general internal medicine) combined. In the surgical department, both urology and orthopedic surgery were relatively large prescribers, mainly for medical intervention prophylaxis and (extended) surgical prophylaxis prescribed on the ward. These tables also show the number of prescriptions in which a protocol was present and followed. Of note, the department of hematology had a $100 \%$ guideline presence for medical prophylaxis and orthopaedic surgery had 100\% protocol presence for extended surgical prophylaxis prescribed on the ward. The identified indications for prophylaxis are summarized in Table 4.

Table 5 shows the antibiotics prescribed. The most prescribed prophylactic antibiotics were trimethoprim/ sulfamethoxazole (32.3\% of total, mainly Pneumocystis jiroveci pneumonia (PCP)-prophylaxis and urological

Table 1 Antimicrobial prescriptions per point prevalence survey

\begin{tabular}{|c|c|c|c|c|c|c|c|c|}
\hline & $\begin{array}{l}\text { Total number of } \\
\text { prescriptions }\end{array}$ & $\begin{array}{l}\text { Prophylactic } \\
\text { prescriptions (\%) }\end{array}$ & $\begin{array}{l}\text { Medical } \\
\text { prophylaxis } \\
(\%)\end{array}$ & $\begin{array}{l}\text { Medical intervention } \\
\text { prophylaxis (\%) }\end{array}$ & $\begin{array}{l}\text { Surgical } \\
\text { prophylaxis } \\
(\%)\end{array}$ & $\begin{array}{l}\text { Antibiotic } \\
\text { prescriptions }\end{array}$ & $\begin{array}{l}\text { Antiviral } \\
\text { prescriptions }\end{array}$ & $\begin{array}{l}\text { Antifungal } \\
\text { prescriptions }\end{array}$ \\
\hline PPS1 & 229 & $60(26.2 \%)$ & $40(17.5 \%)$ & $5(2.2 \%)$ & $15(6.8 \%)$ & 188 & 21 & 20 \\
\hline PPS2 & 261 & 80 (30.7\%) & 67 (25.7\%) & $4(1.5 \%)$ & $9(3.4 \%)$ & 204 & 33 & 24 \\
\hline PPS3 & 259 & 81 (31.3\%) & $62(23.9 \%)$ & 5 (1.9\%) & $14(5.4 \%)$ & 210 & 22 & 27 \\
\hline PPS4 & 271 & 96 (35.4\%) & $68(25.1 \%)$ & $8(3.0 \%)$ & $20(7.4 \%)$ & 225 & 20 & 26 \\
\hline Total & 1020 & 317 (31.1\%) & 237 (23.2\%) & $22(2.2 \%)$ & $58(5.7 \%)$ & 827 & 96 & 97 \\
\hline
\end{tabular}

Divided in antibiotic, antiviral and antifungal prescriptions PPS point prevalence survey. ${ }^{\text {a }}$ surgical prophylaxis given on a ward 
Table 2 Prophylactic antibiotic prescriptions

\begin{tabular}{lllll}
\hline & Prescriptions $(\mathrm{n})$ & Presence of protocol (\%) & According to protocol (\%) & Motivation of non-adherence (\%) \\
\hline Medical prophylaxis (\%) & 141 & $125(88.7 \%)$ & $118(94.4 \%)$ & $1 / 7(14.3 \%)$ \\
Medical intervention prophylaxis & 22 & $13(59.1 \%)$ & $12(92.3 \%)$ & $0 / 1$ \\
Surgical prophylaxis $^{\mathrm{a}}$ & 57 & $42(73.7 \%)$ & $41(97.6 \%)$ & $0 / 1$ \\
Total & 220 & $180(81.8 \%)$ & $171(95.0 \%)$ & $1 / 9(11.1 \%)$ \\
\hline
\end{tabular}

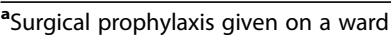

prophylaxis), first-generation cephalosporins (21.8\%, mainly surgical prophylaxis prescribed on the ward) and fluoroquinolones $(20.4 \%$, mainly selective decontamination of the digestive tract in neutropaenic patients).

\section{Discussion}

In this study, we investigated the extent, indications and appropriateness of antimicrobial prophylaxis that was given outside the operating theatre in a tertiary care teaching hospital. A substantial part (31.1\%) of all antimicrobial prescriptions (including antivirals and antifungals) on the wards was for prophylaxis. Almost a quarter of all antibiotic prescriptions concerned prophylaxis. And around $50 \%$ of antiviral and antifungal prescriptions. For most antibiotic medical prophylaxis there was a protocol and adherence to these protocols was high. For antibiotic prophylaxis around non-surgical interventions and for surgical prophylaxis given on the ward a protocol was often not available, but if present, adherence again was high. Antivirals and antifungals were with a few exceptions given according to a protocol.

The percentage of about a third of all antimicrobial prescriptions administered outside the operating theatre being prophylaxis is in line with reports from other tertiary care hospitals in the Netherlands. A study from Rotterdam reported that $34.4 \%$ of hospitalized patients used prophylactic antibiotics, but this included patients using surgical prophylaxis administered in the operating theatre [9]. A study from the Radboud University hospital in the Netherlands reported a percentage of $19.1 \%$ for medical prophylaxis, but only antibiotics were investigated [10]. The annual report on antibiotic use from 50 mainly non-academic hospitals in the Netherlands (Nethmap 2015) reports a percentage of

Table 3 Prophylactic antibiotic prescriptions per specialty/ward

\begin{tabular}{|c|c|c|c|c|c|c|c|}
\hline Internal medicine & $\begin{array}{l}\text { Prescriptions } \\
\text { (n) }\end{array}$ & $\begin{array}{l}\text { Presence of } \\
\text { protocol (\%) }\end{array}$ & $\begin{array}{l}\text { According to } \\
\text { protocol (\%) }\end{array}$ & $\begin{array}{l}\text { Motivation of non- } \\
\text { adherence }\end{array}$ & $\begin{array}{l}\text { Medical } \\
\text { prophylaxis }\end{array}$ & $\begin{array}{l}\text { Medical intervention } \\
\text { prophylaxis }\end{array}$ & $\begin{array}{l}\text { Surgical } \\
\text { prophylaxis }\end{array}$ \\
\hline Internal medicine & 25 & $23(92.0 \%)$ & $23(100.0 \%)$ & - & 23 & 0 & 2 \\
\hline Haematology & 62 & $62(100 \%)$ & $62(100 \%)$ & - & 62 & 0 & 0 \\
\hline Pulmonology & 3 & $3(100 \%)$ & $2(66.7 \%)$ & $0 / 1$ & 1 & 0 & 2 \\
\hline Cardiology & 11 & $11(100 \%)$ & 10 (90.9\%) & $0 / 1$ & 1 & 10 & 0 \\
\hline Gastro-enterology & 8 & $8(100 \%)$ & $8(100 \%)$ & - & 5 & 3 & 0 \\
\hline Psychiatry & $2^{*}$ & $2(100 \%)$ & 2 (100\%) & - & 2 & 0 & 0 \\
\hline \multicolumn{8}{|l|}{ Surgery } \\
\hline General surgery & 7 & $2(28.6 \%)$ & $2(100.0 \%)$ & - & 6 & 0 & 1 \\
\hline $\begin{array}{l}\text { Oral \& maxillofacial } \\
\text { surgery }\end{array}$ & 1 & $0(0 \%)$ & $0(0 \%)$ & - & 1 & 0 & 0 \\
\hline ENT-surgery & 10 & $9(90.0 \%$ & $9(100.0 \%)$ & - & 2 & 1 & 7 \\
\hline Neurosurgery & 5 & $3(60.0 \%)$ & $3(100.0 \%)$ & - & 1 & 1 & 3 \\
\hline $\begin{array}{l}\text { Gynaecology and } \\
\text { obstetrics }\end{array}$ & 3 & $2(66.7 \%)$ & $2(100.0 \%)$ & - & 0 & 0 & 3 \\
\hline $\begin{array}{l}\text { Orthopaedic } \\
\text { surgery }\end{array}$ & 17 & 17 (100\%) & 17 (100\%) & - & 2 & 0 & 15 \\
\hline Thoracic surgery & 1 & $0(0 \%)$ & $0(0 \%)$ & - & 0 & 0 & 1 \\
\hline Urology & 23 & 8 (34.8\%) & $8(100.0 \%)$ & - & 0 & 5 & 18 \\
\hline \multicolumn{8}{|l|}{ Paediatrics } \\
\hline General paediatrics & 16 & $5(31.3 \%)$ & $3(60.0 \%)$ & $0 / 2$ & 10 & 1 & 5 \\
\hline $\begin{array}{l}\text { Paediatric } \\
\text { oncology }\end{array}$ & 26 & 25 (96.2\%) & $20(80.0 \%)$ & $1 / 5$ & 25 & 1 & 0 \\
\hline
\end{tabular}


Table 4 Indications for prophylaxis per specialty

\begin{tabular}{|c|c|c|}
\hline Internal medicine & Indication & Protocol \\
\hline Haematology & $\begin{array}{l}\text { 1. Long-term neutropaenia/selective decontamination of the } \\
\text { digestive tract } \\
\text { 2. Antiviral prophylaxis after chemotherapy }\end{array}$ & $\begin{array}{l}\text { 1. Yes } \\
\text { 2. Yes }\end{array}$ \\
\hline Internal medicine & $\begin{array}{l}\text { 1. PCP and CMV prophylaxis after kidney transplantation } \\
\text { 2. Voiding cysto-urethrography after kidney transplantation } \\
\text { 3. Other PCP-prophylaxis }\end{array}$ & $\begin{array}{l}\text { 1. Yes, protocol on intranet } \\
\text { 2. No protocol on intranet } \\
\text { 3. Yes/no, depends on indication. }\end{array}$ \\
\hline Gastro-enterology & $\begin{array}{l}\text { 1. ERCP } \\
\text { 2. Esophaegeal varix haemorrhage } \\
\text { 3. Immunosuppression for inflammatory bowel disease } \\
\text { 4. Spontaneous bacterial peritonitis prophylaxis }\end{array}$ & $\begin{array}{l}\text { 1. Yes } \\
\text { 2. Yes } \\
\text { 3. Yes } \\
\text { 4. Yes }\end{array}$ \\
\hline Pulmonology & 1. Exacerbation COPD & 1. Yes \\
\hline Cardiology & $\begin{array}{l}\text { 1. Mitraclip } \\
\text { 2. ICD/pacemaker implantation } \\
\text { 3. TAVI-procedure } \\
\text { 4. Endocarditis prophylaxis }\end{array}$ & $\begin{array}{l}\text { 1. Yes } \\
\text { 2. Yes } \\
\text { 3. Yes } \\
\text { 4. Yes }\end{array}$ \\
\hline \multicolumn{3}{|l|}{ Pediatrics } \\
\hline $\begin{array}{l}\text { General paediatrics } \\
\text { (including subspecialties) }\end{array}$ & $\begin{array}{l}\text { 1. NUSS-procedure } \\
\text { 2. Adenotonsillectomy } \\
\text { 3. Recurrent urinary tract infections } \\
\text { 4. ERCP } \\
\text { 5. HIV-prophylaxis in newborns } \\
\text { 6. Prophylactic antibiotics in cystic fibrosis }\end{array}$ & $\begin{array}{l}\text { 1. Yes } \\
\text { 2. No } \\
\text { 3. Yes } \\
\text { 4. No } \\
\text { 5. Yes } \\
\text { 6. No }\end{array}$ \\
\hline Paediatric oncology & $\begin{array}{l}\text { 1. Long-term neutropaenia/selective } \\
\text { decontamination of the digestive tract } \\
\text { 2. PCP-prophylaxis }\end{array}$ & $\begin{array}{l}\text { 1. Yes } \\
\text { 2. Yes }\end{array}$ \\
\hline \multicolumn{3}{|l|}{ Surgery } \\
\hline General surgery & $\begin{array}{l}\text { 1. Stoma reversal } \\
\text { 2. Chronic anastomotic leakage } \\
\text { 3. Non-surgical prophylaxis after Whipple operation } \\
\text { 4. After amputation for osteomyelitis }\end{array}$ & $\begin{array}{l}\text { 1. No protocol } \\
\text { 2. No protocol } \\
\text { 3. No protocol } \\
\text { 4. No protocol }\end{array}$ \\
\hline Urology & $\begin{array}{l}\text { 1. TURP } \\
\text { 2. Ureterorenoscopy } \\
\text { 3. Double-J-catheter replacement } \\
\text { 4. Percutaneous kidney stone removal } \\
\text { 5. Laparoscopic/open nephrectomy } \\
\text { 6. Cryo-ablation of tumor } \\
\text { 7. Bricker bladder surgery }\end{array}$ & $\begin{array}{l}\text { No internal protocols, prescriptions seem based on } \\
\text { international guidelines, no documentation. Standard } \\
\text { surgical prophylaxis according to general surgical guidelines. }\end{array}$ \\
\hline Orthopaedic surgery & 1. Use of osteosynthesis/joint replacement material & 1. Yes \\
\hline $\begin{array}{l}\text { Gynaecology and } \\
\text { obstetrics }\end{array}$ & $\begin{array}{l}\text { 1. Third and fourth degree rupture } \\
\text { 2. Inguinal lymph node dissection }\end{array}$ & $\begin{array}{l}\text { 1. Protocol on intranet, contradicted by local antibiotics } \\
\text { guideline } \\
\text { 2. No mention of antibiotics in protocol }\end{array}$ \\
\hline $\begin{array}{l}\text { Oral \& maxillofacial } \\
\text { surgery }\end{array}$ & 1. Skull fracture & 1. Antibiotics mentioned in protocol, no specifics \\
\hline ENT-surgery & $\begin{array}{l}\text { 1. Surgical prophylaxis } \\
\text { 2. After DRAF-procedure }\end{array}$ & $\begin{array}{l}\text { 1. Yes } \\
\text { 2. No protocol, expert opinion }\end{array}$ \\
\hline Thoracic surgery & 1. TAAA-procedure & 2. No protocol \\
\hline Neurosurgery & $\begin{array}{l}\text { 1. Deep Brain Stimulation placement } \\
\text { 2. CNS Leakage }\end{array}$ & $\begin{array}{l}\text { 1. Yes } \\
\text { 2. No protocol }\end{array}$ \\
\hline
\end{tabular}

medical prophylaxis of $12.7 \%$ [12]. This may indicate a lower proportion of medical prophylaxis in secondary care centers. None of these reports contain indications, information on departments or data on the appropriateness of the prescriptions. A multi-center audit of antibiotic use in France, including both university and non-university hospitals, reported a percentage of medical prophylaxis of $11.2 \%$, comparable to the number found in the Nethmap study [13].

The adherence rate to protocols for medical antibiotic prophylaxis (94.4\%) is high. Most audits of therapeutic antibiotic use report lower percentages of guideline adherence [14]. In the aforementioned study from Rotterdam, therapy was considered appropriate in $70.7 \%$. 
Table $\mathbf{5}$ List of prescribed prophylactic antibiotics per antibiotic class

\begin{tabular}{|c|c|c|c|c|}
\hline & $\begin{array}{l}\text { Number of prescriptions } \\
\text { (\% of total) }\end{array}$ & Medical prophylaxis & $\begin{array}{l}\text { Medical interventional } \\
\text { prophylaxis }\end{array}$ & $\begin{array}{l}\text { Surgical } \\
\text { prophylaxis }\end{array}$ \\
\hline Trimethoprim/sulfamethoxazole & $71(32.3 \%)$ & 59 & 3 & 9 \\
\hline First generation cephalosporins & $48(21.8 \%)$ & 3 & 7 & 38 \\
\hline Fluoroquinolones & $45(20.4 \%)$ & 42 & 2 & 1 \\
\hline Small spectrum penicillins & $19(8.6 \%)$ & 15 & 3 & 1 \\
\hline Amoxicillin/clavulanic acid & $9(4.1 \%)$ & 7 & 1 & 1 \\
\hline Third generation cephalosporins & $5(2.3 \%)$ & 1 & 3 & 1 \\
\hline Broad spectrum penicillins & $4(1.8 \%)$ & 1 & 0 & 3 \\
\hline Colistine & $4(1.8 \%)$ & 4 & 0 & 0 \\
\hline Macrolides & $3(1.4 \%)$ & 3 & 0 & 0 \\
\hline Aminoglycosides & $3(1.4 \%)$ & 1 & 1 & 1 \\
\hline Metronidazole & $2(0.9 \%)$ & 1 & 0 & 1 \\
\hline Clindamycin & $2(0.9 \%)$ & 1 & 1 & 0 \\
\hline Nitrofurantoine & $2(0.9 \%)$ & 2 & 0 & 0 \\
\hline Meropenem & $1(0.4 \%)$ & 0 & 1 & 0 \\
\hline Second generation cephalosporins & $1(0.5 \%)$ & 0 & 0 & 1 \\
\hline Trimethoprim & $1(0.5 \%)$ & 1 & 0 & 0 \\
\hline Total & $220(100 \%)$ & 141 & 22 & 57 \\
\hline
\end{tabular}

The high guideline adherence rate in prophylaxis may be explained by the fact that prophylaxis is more easily protocolized than therapy.

This study has several strengths. It was done on four different time points, involving all wards, and the manual identification of antimicrobial prescriptions was validated by a list from the computerized medication order entry system. This implies that it is unlikely that prescriptions were overlooked. Additionally, it provides an overview of the specific indications, existence of and adherence to protocols, and differences between medical specialties.

Limitations are that some indications might have been missed, for instance if certain procedures are never performed on Mondays. The radiology department documents antimicrobial use in a different system, and their patients do not show up in the medical records. This might have led to an underestimation of prophylaxis for medical interventions. Also, documentation of indications was sometimes poor. We finally decided to exclude the intensive care unit in our study, despite the common use of prophylactic selective decontamination of the gastrointestinal tract, because our intensive care unit was working with a different medication ordering system.

From our study, the most important target for improvement is the absence of protocols for antibiotic prophylaxis during medical interventions. However, considering the multitude of interventions and the complex cases in a tertiary care hospital, some cases are to be left to the expertise of the treating clinician. Surgery in children with specific congenital malformations and complex surgical patients are examples where antimicrobial prophylaxis might be indicated, but where standardization will be very difficult. Appropriateness in these cases is therefore difficult to assess. An additional problem is that despite the presence of protocols, the evidence for some indications is limited. For urology, evidence is available for transurethral resection of the prostate and prostate biopsy, but for all other procedures it is unclear whether prophylaxis is necessary $[15,16]$. Also for orthopedic surgery, where the use of extended surgical prophylaxis (prescribed on the ward) in revision surgery is clearly protocolized, the evidence is lacking [17]. For most cardiologic procedures, there are no randomized controlled trials on prophylactic antibiotic use. Even for PCP prophylaxis, despite its wide-spread use, there are three different dosing schemes in use and unclear evidence on which one is preferable [18].

Further studies should focus on the role of antimicrobial prophylaxis given outside the operating theatre in non-tertiary care centers. It is possible that in non-university hospitals, with their different case-mix, e.g., less haematological and solid organ transplant patients and less complex surgical procedures, prophylaxis will be a smaller part of total antimicrobial use. Additionally, the outpatient clinic would be interesting to investigate, as many prophylactic antimicrobial prescriptions may be initiated or continued there. 


\section{Conclusions}

A third of antimicrobial prescriptions prescribed outside the operating theatre concerns prophylaxis. Whereas in our hospital antimicrobial prophylaxis outside the operating theatre in general turned out not to be an important target for improving antimicrobial use, in particular prophylaxis for non-surgical interventions and surgical prophylaxis given on the ward deserves attention from each antimicrobial stewardship team, in particular the availability of protocols for these indications.

\section{Abbreviations}

DOT: Days on therapy; ECDC: European Center for Disease Control; PCP: Pneumocystic jiroveci pneumonia; PPS: Point prevalence survey; RCT: Randomized controlled trial

\section{Acknowledgments}

No additional acknowledgments.

\section{Funding}

Not applicable.

\section{Availability of data and materials}

The datasets used and analyzed during the current study are available from the corresponding author on reasonable request.

\section{Authors' contribution}

CEV, RMvH and JMP conceived the study. JWTD collected and analyzed data and drafted the manuscript. All authors interpreted the data, and critically revised the manuscript. All authors read and approved the final manuscript.

\section{Competing interests}

The authors declare that they have no competing interests.

\section{Consent for publication}

Not applicable.

\section{Ethics approval and consent to participate}

This observational point-prevalence study of patient files was performed in the context of a quality improvement project. Therefore, approval of the medical ethics committee was not required.

\section{Publisher's Note}

Springer Nature remains neutral with regard to jurisdictional claims in published maps and institutional affiliations.

\section{Author details \\ ${ }^{1}$ Academic Medical Center, Amsterdam, the Netherlands. ${ }^{2}$ Pressent Address: Julius Center for Health Sciences and Primary Care, University Medical Center Utrecht, Huispostnr. STRATENUM 6.131, Postbus 85500, 3584 CG Utrecht, the Netherlands. ${ }^{3}$ Department of Microbiology, Academic Medical Center, Amsterdam, the Netherlands. ${ }^{4}$ Department of Internal Medicine, Academic Medical Center, Amsterdam, the Netherlands. ${ }^{5}$ Department of Hospital Pharmacy, Academic Medical Center, Amsterdam, the Netherlands.}

Received: 5 December 2016 Accepted: 28 March 2017

Published online: 21 April 2017

\section{References}

1. Bowater RJ, Stirling SA, Lilford RJ. Is antibiotic prophylaxis in surgery a generally effective intervention? Testing a generic hypothesis over a set of meta-analyses. Ann Surg. 2009;249:551-6.

2. Sutcliffe JA, Briggs JH, Little MW, McCarthy E, Wigham A, Bratby M, et al. Antibiotics in interventional radiology. Clin Radiol. 2015;70:223-34.

3. Freifeld AG, Bow EJ, Sepkowitz KA, Boeckh MJ, Ito Jl, Mullen CA, et al. Clinical practice guideline for the use of antimicrobial agents in neutropenic patients with cancer: 2010 update by the infectious diseases society of america. Clin Infect Dis. 2011;52:e56-93.
4. Khashab MA, Chithadi KV, Acosta RD, Bruining DH, Chandrasekhara V, et al Antibiotic prophylaxis for Gl endoscopy. Gastrointest Endosc. 2015:81:81-9.

5. Health Council of the Netherlands: Antibiotics in hospitals: prophylaxis and antibiotic stewardship. https://www.gezondheidsraad.nl/sites/default/files/ 201512_antibiotica_in_ziekenhuizen.pdf. Accessed 6 Feb 2016

6. Usluer G, Ozgunes I, Leblebicioglu H, Turkish Antibiotic Utilization Study G. A multicenter point-prevalence study: antimicrobial prescription frequencies in hospitalized patients in Turkey. Ann Clin Microbiol Antimicrob. 2005:4:16.

7. Seaton RA, Nathwani D, Burton P, McLaughlin C, Mackenzie AR, Dundas S, et al. Point prevalence survey of antibiotic use in Scottish hospitals utilising the Glasgow Antimicrobial Audit Tool (GAAT). Int J Antimicrob Agents. 2007;29:693-9.

8. Lee C, Walker SA, Daneman N, Elligsen M, Palmay L, Coburn B, et al. Point prevalence survey of antimicrobial utilization in a Canadian tertiary-care teaching hospital. J Epidemiol Glob Heal. 2015;5:143-50.

9. Akhloufi H, Streefkerk RH, Melles DC, de Steenwinkel JE, Schurink CA, Verkooijen RP, et al. Point prevalence of appropriate antimicrobial therapy in a Dutch university hospital. Eur J Clin Microbiol Infect Dis. 2015;34:1631-7.

10. van Spreuwel PC, Blok H, Langelaar MF, Kullberg BJ, Mouton JW, Natsch S. Identifying targets for quality improvement in hospital antibiotic prescribing. Neth J Med. 2015;73:161-8.

11. ECDC. European Centre for Disease Prevention and Control. Point prevalence survey of healthcareassociated infections and antimicrobial use in European acute care hospitals. Stockholm: ECDC; 2013. http://ecdc.europa.eu/en/ publications/Publications/healthcare-associated-infections-antimicrobial-usePPS.pdf. Accessed 6 Feb 2016

12. Nethmap. Nethmap 2015: Consumption of antimicrobial agents and antimicrobial resistance among medically important bacteria in the Netherlands. http://www.wur.nl/upload_mm/2/2/2/0ab4b3f5-1cf0-42e7a460-d67136870ae5_NethmapMaran2015.pdf. Accessed 6 Feb 2016

13. Robert J, Péan $Y$, Varon E, Bru J-P, Bedos J-P, Bertrand $X$, et al. Point prevalence survey of antibiotic use in French hospitals in 2009. J Antimicrob Chemother. Oxford University Press2012;67:1020-6.

14. van den Bosch CM, Geerlings SE, Natsch S, Prins JM, Hulscher ME. Quality indicators to measure appropriate antibiotic use in hospitalized adults. Clin Infect Dis. 2015;60:281-91.

15. Bootsma AM, Laguna Pes MP, Geerlings SE, Goossens A. Antibiotic prophylaxis in urologic procedures: a systematic review. Eur Urol. 2008:54:1270-86.

16. Grabe M, Bartoletti R, Bjerklund Johansen TE. Guidelines on Urological Infections. 2013; https://uroweb.org/wp-content/uploads/18_Urologicalinfections_LR.pdf. Accessed 6 Feb 2016.

17. Gradl G, Horn C, Postl LKL, Miethke T, Gollwitzer H. Antibiotic prophylaxis in primary and revision hip arthroplasty: what is the evidence? Orthopade. 2011:40:520-7.

18. Stern A, Green H, Paul M, Vidal L, Leibovici L. Prophylaxis for Pneumocystis pneumonia (PCP) in non-HIV immunocompromised patients. In: Stern A, editor. Cochrane Database Syst. Rev. Chichester: Wiley; 2014.

Submit your next manuscript to BioMed Central and we will help you at every step:

- We accept pre-submission inquiries

- Our selector tool helps you to find the most relevant journal

- We provide round the clock customer support

- Convenient online submission

- Thorough peer review

- Inclusion in PubMed and all major indexing services

- Maximum visibility for your research

Submit your manuscript at www.biomedcentral.com/submit
) Biomed Central 